\title{
ESPACIO LITÚRGICO MEDIEVAL VS. ESCENA. EL ANTECORO DE LA CATEDRAL DE LAON Y EL EXORCISMO PÚBLICO DE NICOLE OBRY $Y^{*}$
}

\author{
Eduardo CARrero \\ Universitat Autònoma de Barcelona \\ Eduardo.Carrero@uab.cat
}

A las puertas de la primavera de 1566, Laon vivió un acontecimiento espeluznante. Nicole Obry, una joven de Verins que sufría una posesión diabólica desde noviembre del año anterior, fue llevada a la ciudad para ser exorcizada de nuevo. El proceso venía de meses atrás, tras infructuosos intentos en su localidad natal y otros en la iglesia de Notre-Dame de Liesse -donde ya se había conseguido conjurar a veintiséis demonios-y en la localidad de Pierrepont, donde las reliquias de San Restituto hicieron huir al diablo Legio. La decisión, más política que otra cosa, fue llevarla hasta Laon. En la catedral, le fue practicado un largo exorcismo público durante varios días, tras el que fue liberada de los restantes tres diablos que aún ocupaban su cuerpo. En acción de gracias, todos los 8 de enero se pasó realizar una procesión, fundada desde el arcedianato catedralicio.

La historia tiene un mayor calado. En 1566, el preboste Jean Boulaese redactó un corto texto sobre el acontecimiento que, en dieciséis páginas, se ilustró con un grabado desplegable resumiendo la historia narrada, publicación seguida algo después por una segunda, como tendremos oportunidad de ver. En ambos casos, la historia de Nicole tuvo como trasfondo una fuerte defensa del dogma de la Eucaristía y el culto a los Santos, los dos instrumentos salvíficos de la joven, en el contexto de la lucha político-religiosa contra los hugonotes, a los que el relato se refiere en varias ocasiones y convertidos en

${ }^{*}$ Este trabajo se encuadra en el Grupo de Investigación Consolidado LAIREM (AGAUR 2014 SGR 894), en el Proyecto I+D+i «Aragonia cisterciensis. Espacio y función en los monasterios de la orden del císter en la Corona de Aragón» (HAR2015-63772-P). 
los críticos opositores a un proceso que no dudaron en calificar de engaño, montaje y teatro ${ }^{1}$.

Las dos publicaciones de Boulaese fueron acompañadas por sendos grabados, ilustrando la narración de lo sucedido en Laon e interesantes por varios motivos. El más antiguo de los dos se trazó con una abigarrada composición, marcada por presentar -digámoslo así- una suerte de narración de carácter cuasi teatral (Fig. 1), bajo el epígrafe Le miracle que Jesus Christ au S. Sacrement ha consummé a Laon ceste anné 1566, au vif representé, et script en cinq langues ${ }^{2}$. Dividido en tres registros verticales, la imagen se diseñó mediante una suerte de escenario que se corresponde con dos niveles de público en dos pisos, en tanto que la franja central se sitúa bajo cuatro arquerías lobuladas, a la manera del marco de un escenario. La acción comienza en el arco de la derecha, bajo el siguiente a la izquierda se celebra misa y, en los dos últimos, la escena más compleja se sucede sobre un estrado, intencionadamente representado mediante los tablones en perspectiva que integran la plataforma. De hecho, se trata de la alta tarima que se elevó frente al antecoro de la catedral para celebrar el exorcismo, pero que, en el grabado que nos ocupa, fue también usada para articular compositivamente parte del relato.

Comenzando la lectura por la derecha y siguiendo la leyenda que explica el grabado, una larga procesión de cruces alzadas y prelado bajo palio entra en la catedral recorriendo la zona inferior del cuadro. Tras el obispo, y en perspectiva, un grupo de hombres lleva en brazos a la gesticulante posesa. En último término se acerca un grupo de hombres y mujeres tocados con gorro y portando libros, los críticos hugonotes. En uno de los arcos del escenario, con una clara voluntad de aislar y subrayar la escena mediante las marcadas columnas y la perspectiva, el obispo celebra una eucaristía ante el altar de la Virgen del Púlpito - uno de los dos que se abrían en el antecoro catedralicio-, acompañado de dos acólitos sosteniendo unas humeantes hachas encendidas. Cabe destacar la mitra depositada sobre el altar y el hecho de que el momento elegido para la representación fuera, precisamente, el alzamiento de la hostia por el ministro, adelantando y subrayando el carácter salvífico y milagroso de Corpus Christi en el exorcismo ${ }^{3}$. Como aclara la leyenda, se trata de la

${ }^{1}$ Cfr. Irena Backus, Le miracle de Laon. Le déraisonnable, le raisonnable, l'apocalyptique et le politique dans les récits du miracle de Laon (1566), París, Vrin, 1994, y Denis Crouzet, «A Woman and the Devil: Possession and Exorcism in Sixteenth-Century France», en Changing Identities in Early Modern France, ed. de Michael Wolfe, Durham-Londres, Duke University Press, 1997, pp. 191-215.

${ }^{2}$ Utilizo la copia de la parisina Bibliothèque Sainte-Geniviève, Réserve, 8 D 11058. Para las ediciones del texto, véanse las notas siguientes.

${ }^{3} \mathrm{Su}$ comparación con escenas paralelas de adoración eucarística, como la Misas de san Gregorio y san Martín, parece algo redundante, $c f r$. Laura Weigert, French Visual Culture and the Making of Medieval 




Fig. 1. Grabado de Le miracle de Laon en Laonnois représenté au vif et escript en latin, françoys, italien, espaignol et allemant, 1566. París, Bibliothèque Sainte-Geneviève, 8 D 11058 RES (P.2 BIS).

Eucaristía que el prelado celebró tras entrar en la catedral, en tanto que Nicole era depositada en el cadalso que se había levantado al efecto, en el que también se situaron los hombres del rey, el cabildo y los médicos que refrendaron la veracidad del caso. Cabe destacar aquí que, en la parte superior del

Theater, Nueva York, Cambridge University Press, 2015, pp. 204-213. 


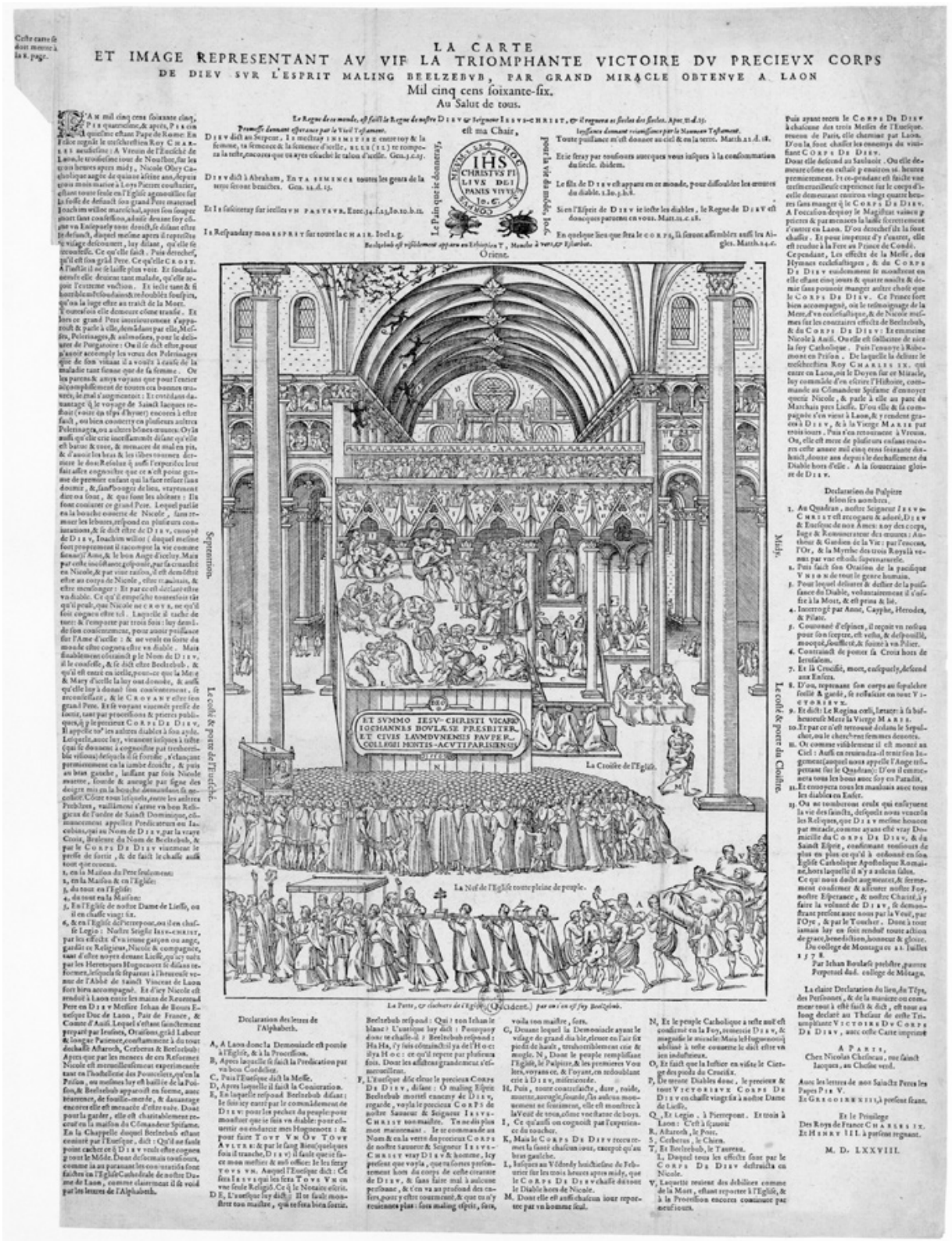

Fig. 2. Miracle de Laon. Ilustración que acompañaba el impreso editado por Nicolas Chesneau en 1578 (C) París, Bibliothéque Nationale de France.

grabado, como en una galería, otros tantos hombres reputados -las autoridades civiles- se dispusieron a contemplar y comentar los hechos, 
excepcionalmente localizados «bajo las bóvedas, alrededor de la nave» ${ }^{4}$. Prosiguiendo la narración, en el siguiente escenario -el del tablado-, el obispo con la hostia consagrada levantada en la mano se acerca a Nicole que, entre espasmos y contorsiones, es sujetada por varios hombres entre el gentío de prohombres que rodean al prelado. Los efectos salvíficos de la eucaristía se dejan sentir de inmediato. Primero, la endemoniada Nicole quedó exhausta, sin sentir nada, arrodillada y con las manos a la espalda. Así fue mostrada al público asistente que se agolpaba gritando para verla, representado a pie de estrado, junto al comienzo de la procesión con la que iniciábamos la historia. Finalmente, tras la Nicole derrotada, una nueva, salvada del diablo por acción del obispo exorcista y la milagrosa eucaristía, aparece arrodillada recibiendo la bendición de éste y adorando la hostia, obrándose así la curación, revestida de sentido teológico y político.

Como comentábamos arriba, la cuestión no quedó ahí. Las autoridades eclesiásticas querían que el papado confirmara la curación de Nicole como milagro de la Eucaristía y los santos y la maquinaria propagandística contra la Reforma protestante se puso en funcionamiento. Se pergeñaron nuevos textos relativos al maravilloso acontecimiento entre 1570 y 1571 , en los que ahora también intervino el deán de la catedral Christophe d'Hericourt, en tanto que testigo ocular del exorcismo de Nicole ${ }^{5}$. La edición de éstos se acompañó ahora por un grabado mayor, más complejo y muy detallado que ilustraba la historia y que Boulaese volvió a publicar en París en un gran panfleto editado en 1578 (Fig. 2) ${ }^{6}$. De hecho, el impreso se concibió a la manera de los grabados para peregrinos que se entregaban en distintos centros de culto católico de Europa, entre los que me gustaría destacar aquí el imprimido para el Año santo romano de 1575 -obra de Antoine Lafréry-, las buletas del cabildo de la catedral de Oviedo para los romeros a la Cámara Santa o las célebres compostelas, para los peregrinos a Santiago. En todos los casos se trataba de una cultura del recuerdo, en unas ocasiones basada en un texto recogiendo inventarios de reliquias, narración de milagros o descripción de

${ }^{4}$ Le Miracle de Laon en Lannoys, représenté au vif et escript en latin, françoys, italien, espaignol et allemant, à Cambray, chees Pierre Lombard, 1566, ed. de Anna Hélène Chaubard, Lyon, Sauvegarde historique, 1956, y Gillaume Postel y Jean Boulaese, De summopere (1566) et Le miracle de Laon (1566), ed. de Irena Backus, Ginebra, Droz, 1995.

${ }^{5}$ Édouard Fleury, Cinquante ans de l'histoire du chapitre de N.-D. de Laon, procès-verbaux et délibérations du 22 juin 1541 au 15 juillet 1594, Laon-París, Padiez-Dumoulin, 1875, p. 90, n. 2.

${ }^{6}$ Christophe d'Héricourt y Jean Boulaese, Recueil de textes et documents concernants le miracle de Laon, BnF, MS Lat 3224, pp. 43-47, Jean Boulaese, L'Abbrégée Histoire du grand miracle par nostre Sauveur et Seigneur Jésus-Christ en la saincte hostie du sacrement de l'autel, faicte à Laon, 1566, París, T. Belot, 1573, e Id., Le thrésor et entière historie de la triomphante victoire du corps de Dieu sur l'esprit maling Beelzebut, obtenué à Laon l'an mil cinq cens soixante six, París, Nicolas Chesneau, 1578. 
invenciones. En otras tantas - como en Laon-, los textos fueron acompañados de una ilustración más o menos trabajada: desde la imagen de las cruces en Oviedo, a las visitas a las reliquias de las siete iglesias romanas o, en el caso que aquí nos ocupa, una compleja narración de todo el milagro eucarístico ocurrido en la catedral.

\section{El grabado de 1578}

Si lo comparamos con el primer grabado, la ilustración realizada para el gran desplegable de 1578 abrió el objetivo y amplió el escenario en el que se sucede la historia a un interior de la catedral, que superaba con creces la sucesión de escenas en torno al cadalso, de la edición de 1566. La imagen pasó a tomar una instantánea de la nave de la catedral desde su puerta oeste por la que, tal y como reza el pie, «huyó Belcebú» tras el exorcismo. Cabe destacar que la ilustración ocupa el centro del panfleto, en tanto que a su alrededor se sucede una detalladísima explicación del milagro mediante un extenso encabezamiento también ilustrado y una larga leyenda que se desarrolla por los laterales y zona inferior del grabado. Ésta acaba con el nombre del impresor parisino Nicolas Chesneau y la firma el propio Jean Boulaese el 21 de julio de 1578 , con una clara exaltación del triunfo del catolicismo a partir del Corpus Christi.

En la cabecera del impreso, el título ya nos pone en situación al titularlo La carte et image representant au vif la triomphante victoire du précieux corps de Dieu sur l'esprit maling Beelzebub, par grand miracle obtenue a Laon. Mil cinq sens soixante-six. Au salut de tous. Un subtítulo recoge la proclama entonada por las voces del cielo, tras la trompeta del séptimo ángel en el Apocalipsis: «A nuestro Señor y a su Cristo pertenece el dominio del mundo y reinará por los siglos de los siglos» $($ Ap 2, 15). Debajo, la imagen de una hostia con diversas inscripciones. En el centro, el anagrama de Cristo $I H S$, rodeado por una referencia a la eucaristía tomada del evangelio de Lucas (Lc 22,19) y alusión al discurso eucarístico de Cristo en el evangelio de Juan (Jn 6, 51), uno de cuyas frases también aparece rodeando tres lados de la hostia: Le pain que je donneray, ets ma chair pour la vie du monde. Los textos conectan claramente con los moldeados en las formas, mediante los hostieros de forja con los que se elaboraban.

A renglón seguido, los dibujos de una mosca y un escarabajo acompañados de la inscripción «Belzebú apareció claramente con aspecto de un etíope, de mosca y de escarabajo». Si Belcebú, el señor de las moscas y personificado en pequeño etíope o escarabajo es común en la literatura al respecto, 
la descripción e ilustración enlazan con el relato y mensaje final de todo el milagro de Laon, centrado en el dogma de la Eucaristía triunfante y su poder salvífico sobre el diablo ${ }^{7}$. Por fin, cerrando el encabezamiento, a ambos lados del mensaje eucarístico de la hostia, dos columnas de citas recogen a izquierda y derecha, fragmentos del Antiguo y Nuevo Testamentos referentes a la promesa de salvación del pueblo de Dios, en ocasiones con un claro sesgo apocalíptico (Gn 22, 18, Ez 34, 23, Jn 10, 11, J1 3, 1, Mt 28, 18, Mt 28, 20, Mt $24,28)$, y a la lucha contra el diablo (Gn 3, 15, Jn 3, 8, Mt 12, 28)

El resto del texto discurre por los otros tres lados de la imagen, estructurada en dos secciones especialmente interesantes. La columna izquierda y aproximadamente la mitad de la derecha explican el milagro en detalle. Se trata de la narración de la misma sucesión de acontecimientos que ya se había incluido en el impreso de 1566. El relato se acompañó por una auténtica leyenda referente a la imagen central. En la zona inferior de la escena e indicada con las letras del abecedario se explicaron los distintos episodios del suceso, dispuestos en orden cronológico desde la letra A y que pueden seguirse así en todo el dibujo. En la columna derecha, otra leyenda numerada del uno al trece describe varias zonas de la catedral, interesantes para el contenido dogmático del relato. En paralelo, el ilustrador tuvo un claro interés en indicar las zonas del edificio, que aparecen subrayadas mediante diversos epígrafes tanto en el interior como tras los límites del grabado: los puntos cardinales, y a sur y norte respectivamente, la puerta del claustro y el obispado. El escenario es el transepto -Le croissé de l'Église-, con el antecoro como proscenio9.

\section{El exorcismo narrado}

El relato ilustrado en nuestro grabado no difiere en exceso ni en el fondo ni en la forma de su predecesor, sólo amplia el foco del escenario (Fig. 3). La historia de Nicole vuelve a dar comienzo con la comitiva que la llevó desde Ory, hasta la catedral de Laon. Así atraviesa la nave central, en una forma circular, que es comienzo y fin de la historia. La cabeza de la procesión aparece en un segundo plano, en la nave este del transepto, principiada por

${ }^{7}$ No olvidemos que en el lecho de Nicole fue encontrado un demoníaco escarabajo y, en Vervins, el diablo ya se había materializado en mosca.

${ }^{8}$ Hay notables desajustes entre la forma de cita de los versículos de la Biblia y el sistema actual.

${ }^{9}$ Para referirme a la estructura que cerraba el coro capitular de la catedral en el transepto, utilizaré indistintamente la palabra española antecoro y la francesa jubé. Lo hago sólo con el fin de evitar reiteraciones, y nunca en referencia a la acepción de sesgo determinista que en ocasiones se le ha concedido, $c f r$. Eduardo Carrero Santamaría, «Centro y periferia en la ordenación de espacios litúrgicos: Las estructuras corales», en Hortus Artium Medievalium, 14 (2008), pp. 159-178. 


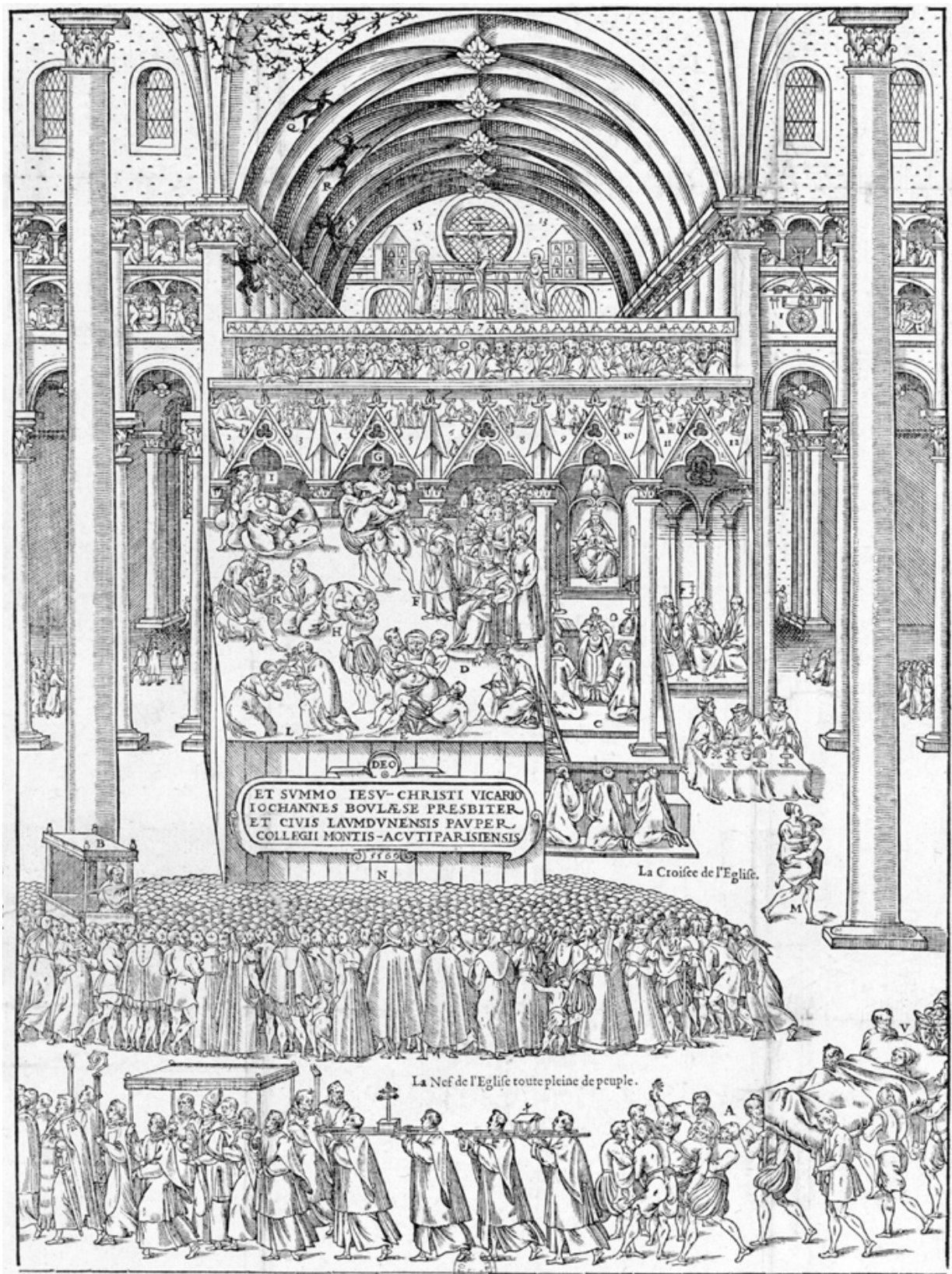

Fig. 3. Miracle de Laon. Detalle del grabado central.

los ceroferarios y el portador de la cruz. Continúa por el transepto, fuera de nuestra visión, para reaparecer en primer plano con su zona más importante, representándose a los integrantes a los que interesó referir: el alto clero bajo 
palio con el obispo a la cabeza, rodeados por hachones y seguidos por las reliquias sobre andas. Tras éstas, un lecho en el que se revuelve la endemoniada es transportado por varios hombres (A). La procesión se extiende con el último episodio de la historia y el final de la comitiva, visible en el extremo opuesto del transepto. Pero no adelantemos acontecimientos. Con la llegada de Nicole a la catedral, en segundo plano sermonea «un buen franciscano» sobre el púlpito de la catedral, ante una contenida muchedumbre como reza el epígrafe respectivo: La nef de l'église, toute pleine de peuple. De hecho, el gentío escucha sus palabras y observa el acontecimiento, que se sucede en el tablado montado frente al antecoro catedralicio (B). La leyenda también alude a los que contemplan la acción desde la zona alta, en donde con la letra O identifica a los jueces con los hombres que ocupan el púlpito del antecoro bajo el Calvario que lo coronaba. El proceso fue seguido en detalle por las autoridades civiles que convocaron a médicos que analizaron paso a paso la situación, con el fin de determinar si, como decían los hugonotes, todo era un fraude para exaltar la eucaristía o, por el contrario, se había obrado el milagro $^{10}$.

La superficie del jubé se organiza en dos zonas, una primera libre a la derecha y la que, ocultando parcialmente el mismo, recibió la construcción del cadalso para el exorcismo. En el antecoro se abre la capilla de la Virgen del Púlpito, a la que se dedica una eucaristía oficiada por el prelado (C) y, algo más allá, tres hombres se sitúan bajo el pórtico del jubé y, delante de ellos, otros tres venden reliquias sobre una mesa.

A continuación, la acción se traslada al cadalso. En su frente, un gran epígrafe refiere al autor del texto, Jean Boulaese: DEO ET SUMMO IESVCHRISTI VICARIO IOCHANNES BOULAESE PRESBITER ET CIVIS LAUMDUNENSIS PAUPER COLLEGI MONTISACUTI PARISIENSIS. Sobre el entarimado, entre las letras D y L, se desarrolla el exorcismo en seis episodios, entre una Nicole trasmutada en un monstruo deforme que se revuelve y rebela $(\mathrm{D}, \mathrm{G}, \mathrm{I})$ y la sanación volviendo a la apariencia física de una joven de dieciséis años $(\mathrm{H}, \mathrm{K}, \mathrm{L})^{11}$. La sanación se produce al invocar el

\footnotetext{
${ }^{10}$ Contamos, incluso, con las actas de los médicos testigos del asunto, personal civil y eclesiásticos, publicadas por J. Roger, Histoire de Nicole de Vervins, d'après les historiens contemporains et témoins oculaires, ou Le triomphe du Saint Sacrament sur le démon a Laon en 1566, París, H. Plon Imprimeur éditeur, 1863. En el exclusivo caso de las opiniones médicas, Louis Langlet, Étude médicale d'une possession au XVI siècle. Nicole Obry, dite Nicole de Vervins, 1566, Reims, Matot-Braine Imprimeur-librarieéditeur, 1910, pp. 87-101, y, con las deliberaciones del propio cabildo catedralicio, Fleury, Cinquante ans de l'histoire, ob. cit., pp. 178-180.

${ }^{11}$ Los distintos estados por los que pasó fueron analizados desde una perspectiva médica, queriendo identificarse con distintos grados de histeria, cfr. Langlet, Étude médicale, ob. cit., pp. 59-83.
} 

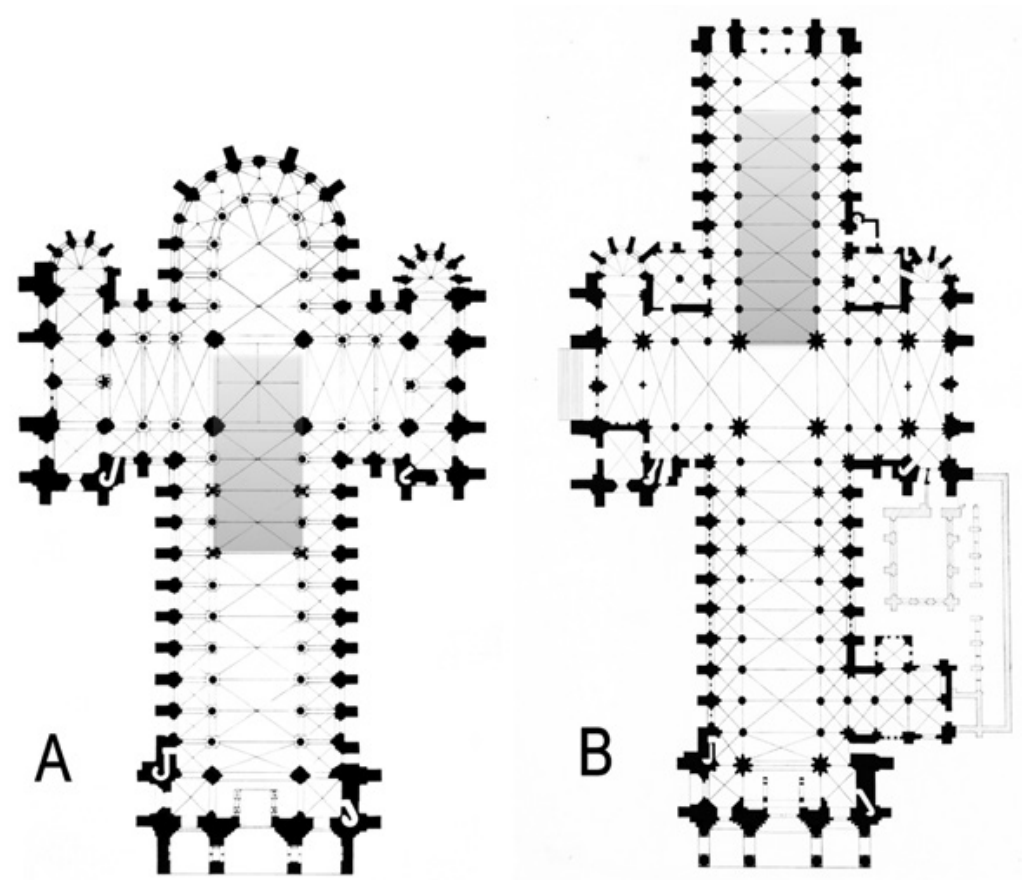

Fig. 4. Catedral de Laon. A. Proyecto inicial con la posición del coro y trascoro, según Fernie.

B. Reconstrucción de la cabecera de 1205 en adelante, con la posición de coro y antecoro.

milagro eucarístico $(\mathrm{H})$, comulgar $(\mathrm{K})$ y adorar la cruz $(\mathrm{L})$. Las seis escenas se sitúan sobre la superficie en perspectiva del tablado, mientras a nuestra derecha la corte episcopal participa de los actos, junto al notario que levanta acta de los acontecimientos. Por fin, con la letra $\mathrm{M}$ se representa a un hombre que porta en los brazos a Nicole por el transepto de la catedral, en tanto que entre las letras P y T se identifica a los distintos demonios que se manifestaron durante el exorcismo, revoloteando en su huida bajo las bóvedas de la catedral: los veintiséis exorcizados en Notre-Dame de Liesse, Legio que había huido en Pierrepont, y Astarot, Cerbero y Belcebú, conjurados en Laon. Todos ellos habían sido expulsados por acción ya del Corpus Christi-Liesse y Laon-, ya de un cuerpo santo como el de San Restituto en Pierrepont. Al huir, Belcebú lo hizo entre humo, explosiones y una niebla que rodeó las torres de la fachada occidental de la catedral, por donde escapó. La liberada y agotada joven aparece finalmente sobre una cama transportada a hombros por cuatro hombres (V). La escena de la incorporación de una Nicole convaleciente cierra la narración del milagro y culmina visualmente la larga procesión con la que se iniciaba el relato: Laquelle reuient des debilitez comme de la Mort, estant reportee à l'Église \& à la Procession encores continué par neuf iours. 


\section{El espacio figurado: El coro de la catedral de Laon}

¿Cuándo y cómo se construyó el cierre de coro de la catedral, que sirvió de proscenio para el exorcismo y tan detalladamente fue representado en el segundo grabado? Laon tuvo una de las historias más fascinantes de adecuación del espacio arquitectónico a una estructura coral y los problemas que esto suponía. Cuando en pleno siglo XII se finalizó el edificio, la catedral tenía un corto presbiterio rodeado por una girola sin capillas radiales. Este limitado espacio obligaba al coro a situarse entre el transepto y la nave con un trascoro, que Eric Fernie localiza vecino a los cuatro pilares acantonados situados en el intercolumnio, entre los dos tramos occidentales inmediatos al transepto (Fig. 4A). Para dicho autor, ambos cuatro pilares señalizaban un importante tramo previo al coro, a la manera de los enormes quire-screens de las catedrales y monasterios ingleses, y en el que se habría localizado el altar de la santa Cruz, datado en el ordinario de Laon ${ }^{12}$. En todo caso, esta organización litúrgica duró poco ya que, entre 1182 y 1183, una bula del papa Lucio III reconocía el número de prebendas catedralicias como ochenta ${ }^{13}$. Podemos imaginar que la aprobación de este espectacular aumento del número de canonjías debió haber sido solicitada por el prelado de Laon en fechas inmediatas. En todo caso, la congregación capitular pasó a estar integrada por nada menos que ochenta canónigos, convirtiéndose en el cabildo catedralicio más populoso de Francia. Esto suponía un duro revés para una organización litúrgica como la descrita, finalizada no hacía mucho y que debía replantearse para dar acomodo en el coro a un cuerpo canonical que superaba con mucho las dimensiones del espacio que se había proyectado y edificado a finales del XII. Esto llevó a la apertura de la catedral con el singular presbiterio rectangular que hoy conservamos. A tal efecto, a comienzo del siglo XIII se derribó la girola y se construyeron cinco tramos de crucería que finalizaban en un testero recto que hacía las funciones de girola (Fig. 4B). Estilísticamente, se mantuvo la compartimentación en cuatro alturas del proyecto original, en un singular ejercicio de unidad de estilo, pero dotando a la catedral de las dimensiones necesarias para instalar una gran sillería de coro, como la que un

\footnotetext{
${ }^{12}$ Eric Fernie, «The Use of Varied Nave Supports in Romanesque and Early Gothic Churches», en Gesta, 23:2 (1984), pp. 107-117 e íd., «La fonction liturgique des piliers cantonnés dans la nef de la cathédrale de Laon», en Bulletin Monumental, 145:3 (1987), pp. 257-266. Una restitución del suntuoso aspecto del altar mayor hacia 1165 en Alain Saint-Denis, «Le maître autel de la cathédrale Notre-Dame de Laon vers 1165», en Bulletin du centre d'études médiévales d'Auxerre (BUCEMA), 4 (2011). [En línea: 14 de junio]. Enlace: <http://cem.revues.org/11841> [Consulta: 3/03/2017]. DOI : 10.4000/cem.11841.

${ }^{13}$ Noticia recogida en Fernie, «La fonction liturgique», art. cit., p. 259.
} 
numeroso cabildo requería, sin alterar en exceso el culto tanto para canónigos como para fieles ${ }^{14}$.

La nueva sillería y sus cierres se habían finalizado en 1228 , fecha del ordinario catedralicio en que ya se alude a los mismos ${ }^{15}$. Se ubicaron en el nuevo y profundo presbiterio, separando la catedral laica entre el transepto y las naves, de la catedral canonical, que ocupaba la cabecera propiamente dicha. Hacia occidente, se edificó un gran antecoro siguiendo los modelos vigentes en toda Europa, que se articulaba mediante una puerta central -la documentada como Porta Speciosa-, dos altares laterales dedicados a la Virgen y a santa Catalina y san Sebastián. El primero, mostraba una imagen con una importante tradición cultual en la catedral. Según parece, había sido la Virgen del altar mayor, realizada en madera y cubierta de metal, que con la ampliación de la cabecera fue trasladada al altar del antecoro, donde permaneció hasta el incendio de $1586^{16}$. Ambos altares estaban cubiertos por una estructura porticada adelantada, sobre la que se situaba el pulpitum, la plataforma elevada desde la que se realizaban lecturas, se cantaba o se interpretaba música.

La importancia social del exorcismo fue tal, que la historia de Nicole fue plasmada visualmente en la propia catedral. Se trata de una noticia poco conocida, procedente de las actas capitulares del siglo XVI, en la que se especifica cómo en el trascoro catedralicio se talló un ciclo con los principales episodios del exorcismo ${ }^{17}$. Pudiéramos pensar que nuestro grabado fue la fuente principal para esas esculturas, pero no ha llegado ninguna pieza medieval o moderna procedente del conjunto coral de la catedral.

No en vano, el antecoro fue profundamente alterado en tiempos modernos. Los altares del jubé fueron rehechos en el siglo xvII, pero fue en pleno siglo XVIII, cuando el cabildo acordó la total renovación de la catedral y, en particular, del altar mayor y de su monumental antecoro, que fue finalmente derribado en agosto de 1773, seguido de unas obras de remodelación de toda

\footnotetext{
${ }^{14} \mathrm{Se}$ trata de un caso muy semejante al de Compostela, cuyo coro tuvo que trasladarse a la nave para favorecer la afluencia de peregrinos al presbiterio de la catedral, donde se concentraba el culto al Apóstol, pero que, dejando el transepto libre, establecía una marcada lejanía entre la sillería y el altar mayor. Con el fin de solucionarlo se proyectó una gigantesca cabecera gótica, cuyas ciclópeas dimensiones muy posiblemente fueron también la causa de que nunca se finalizara, $c f r$. Eduardo Carrero Santamaría, «Arzobispos y obras en Santiago de Compostela entre los siglos XII y XIII. La definición del espacio litúrgico en la catedral», en Reyes y prelados. La creación artística en los Reinos de León y Castilla (1050-1500), ed. de M. D. Teijeira, M. V. Herráez y M. C. Cosmen, Madrid, Sílex, 2014, pp. 173-202.

${ }^{15}$ Martine Plouvier, «Le jubé et le décor du choeur de la cathédrale», en Laon. Une Acropole à la française, dir. de M. Plouvier, 2 vols., Amiens, Cahiers du Patrimoine, 1995, I, pp. 311-320.

${ }^{16}$ Auguste Bouxin, La cathédrale Notre-Dame de Laon. Historique et description, Laon, Imprimerie du Journal de l'Aisne, 1902, pp. 229-230.

${ }^{17}$ Fleury, Cinquante ans de l'histoire, ob. cit., p. 306.
} 
la estructura que prosiguieron hasta 1785. El jubé gótico fue sustituido por una estructura de cierre con dos altares laterales bajo tímpanos a la clásica y una enorme reja de entrada -como todavía puede verse en el dibujo de Tavenier de Joncquières, grabado por Née- ${ }^{18}$. La supresión del antecoro conllevó el problema de dónde localizar a partir de entonces a los lectores y sus atriles en el antecoro, hecho que suscitó no pocos problemas de reorganización del espacio litúrgico, documentados con el nuevo cierre de $1773^{19}$.

\section{La catedral, marco del rito}

Como tendremos ocasión de referir en el siguiente apartado, la estructura narrativa elegida para desarrollar un discurso visual mediante el cual explicar el milagro de la joven endemoniada fue esencialmente complejo. Pero también lo fue el modo en el que se ubicó la escena en el edificio en el que los hechos tuvieron lugar. La acción se desarrolla en todo el transepto de la catedral de Laon, utilizando el desaparecido antecoro gótico de la catedral como proscenio. Este factor debió preocupar al propio Boulaese -en tanto que redactor del texto- $\mathrm{y}$ a su desconocido ilustrador, quienes anotaron las zonas de la catedral donde se desarrolla la historia, pero, además, tomaron la decisión de colocar una segunda leyenda numerada, refiriendo puntualmente elementos de la catedral y su iconografía. El primero de ellos es el reloj situado en el ángulo sureste de la tribuna, de cara al transepto (1). Sobre la esfera aparece una escena de adoración, en la que sólo se ve en detalle lo que parece tratarse de una Virgen sedente con el Niño y un personaje genuflexo a la derecha. La inscripción aclara que se trataba de una Epifanía, amparada por la estrella de Belén y un ángel con una de las trompetas del Apocalipsis, sito en el vértice superior de la maquinaria, como se puntualiza en el número 11 de la leyenda.

Entre los puntos 2 y 12 se recoge todo el programa iconográfico que se esculpió entre los arcos de la arquería del antecoro, quizás evocando las escenas de un largo relieve de la Pasión y Resurrección, como se esculpieron en antecoros coetáneos como los de Bourges (Fig. 5), París o Amiens ${ }^{20}$. Siguiendo las escenas al uso, sólo es destacable la singular sucesión de las apariciones de Cristo resucitado a la Magdalena (9) y a las Marías (10), debido a su mala interpretación por el propio Boulaese. Éste pensó que la primera escena era en realidad la aparición de Cristo a la Virgen, imagen que no se difundió

\footnotetext{
${ }^{18}$ Ibídem, pp. 228-232, y Plouvier, «Le jubé et le décor», art. cit., pp. 316-318.

${ }^{19}$ Mathieu Lours, L'autre temps des cathédrales. Du Concile de Trente à la Révolution française, París, Picard, 2010, pp. 273-274.

${ }^{20}$ Plouvier, «Le jubé et le décor», art. cit., p. 312.
} 
iconográficamente hasta el siglo xv. Por el contrario, ambos episodios fueron esculpidos de la misma guisa en el trascoro sur de Notre-Dame de París (Fig. 6).

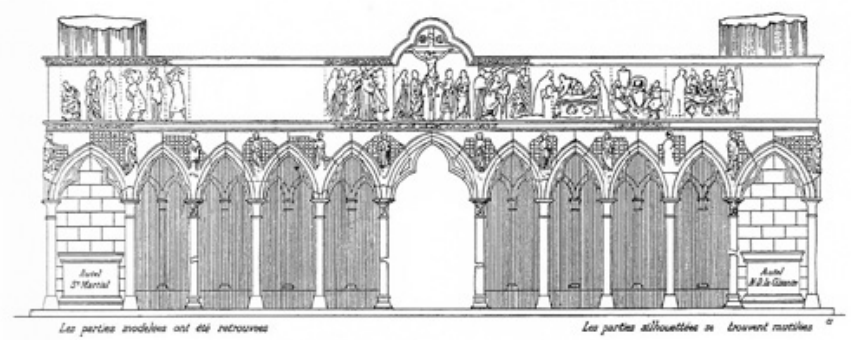

Fig. 5. Restitución del antecoro de la catedral de Bourges, según Gauchery.

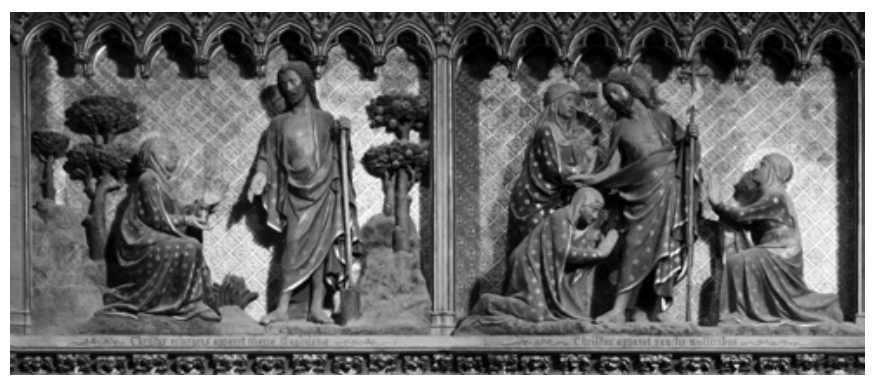

Fig. 6. Notre-Dame de París. Trascoro sur, escenas de la Aparición de Cristo a la Magdalena y a las Santas Mujeres. Foto: Autor.

Hay una última indicación en la larga leyenda descriptiva de la catedral y es la señalada con el número 13. En ésta, se hace una defensa de los santos y el culto a las reliquias ${ }^{21}$, refiriendo en el grabado a dos cajas localizadas en una singular perspectiva a ambos lados del Calvario que remata la estructura del antecoro. Y digo singular, porque no parece quedar muy claro sobre qué se asientan, si están relacionadas con el propio jubé o con el presbiterio de la catedral, ni qué representan. Siguiendo a Yves Delaporte, se trata de dos grandes relicarios que colgaban del muro oriental de la capilla mayor, parece que como en Chartres ${ }^{22}$, en una costumbre bien diferente de la habitual instalación de un gran altar-tesoro en el extremo axial del presbiterio, sustituyendo

${ }^{21} O$ une tomberont ceulx qui ensuyvent la vie des sainctz, desquelz nous veneros les reliques, que Dieu mesme honore par miracle, comme ayans esté vray Domicille du Corps de Dieu \& du Sainct Esprit, confirmant tousiours de plus en plus ce qu'il à ordonné en son Eglise Catholique Apostolique Romaine, hors laquelle il n'ya aulcun salut.

${ }^{22}$ Yves Delaporte, «Le jubé de la cathédrale de Laon et l'autel de l'image», en Mémoires de la société archéologique d'Eure-et-Loir, 16 (1923-36), pp. 143-148. 
al altar de prima. Sea como fuere, el mensaje de redención a partir del culto al Corpus Christi y a la memoria de los Santos quedó perfectamente subrayado.

\section{Liturgia, teatro y uso del espacio en el exorcismo de Nicole Obry}

Un elemento que ha interesado recientemente sobre el grabado del exorcismo de Nicole en la catedral es su interpretación desde una perspectiva teatral $^{23}$. El elemento clave es el cadalso, el tablado elevado frente al antecoro con el fin de hacer pública una ceremonia que solía realizarse en lugares apartados de ojos curiosos y que, en Laon, llegó convertirse en una peligrosa costumbre. El 10 de junio de 1592, una joven de doce o trece años llamada Barbe de Landricourt fue sometida a otro exorcismo. A tal fin volvió a montarse el cadalso en el antecoro catedralicio, entre las capillas de la Virgen y de san Sebastián. Édouard Fleury recoge cómo, durante las deliberaciones capitulares de 1592, se decidió construir este échaffaut ou théâtre para realizar el exorcismo, aunque quizás la noticia más jugosa sea la de 1603, cuando una tercera endemoniada apareció en Laon. La joven Pasquette le Jeune gesticulaba y se contorsionaba como unas décadas antes lo había hecho Nicole Obry, por lo que volvió a instalarse el théatre en la catedral, aplicándosele reliquias de santos con la intención de sanarla. Pero Pasquette no sanó. Fue remitida a los médicos que se ocuparon de ella, acabando las posesiones definitivamente, sólo evocadas por la procesión anual en recuerdo del «milagro» que se había obrado sobre Nicole ${ }^{24}$.

Volviendo a nuestro grabado, la masiva asistencia de espectadores y la auténtica apertura de la catedral a unos asistentes que ocupan el edificio en su totalidad inciden en un carácter escenográfico - «performativo», como ahora se dice-, que podría llevarnos rápidamente a pensar en teatros. Personalmente, creo que debemos medir hasta qué punto el tema puede extrapolarse de esta forma. Evidentemente, la reflexión se hace muy cuesta arriba. No hay duda, el teatro clásico, entendido como drama literario representado por actores en una arquitectura construida ex profeso no existió durante la Edad Media. Las farsas callejeras bajomedievales usaban estructuras de madera que elevaran la acción sobre el suelo. Del mismo modo, la liturgia teatralizada hacía uso de espacios altos que mejoraran la visión de los fieles. El exterior del coro siempre fue usado como un lugar en el que dar cita a unos espectadores que tenían vetado el acceso al interior a la capilla mayor. Cuando la estructura coral se situaba en el presbiterio del edificio -como era habitual-,

${ }^{23}$ Weigert, French Visual Culture, ob. cit., pp. 191-218.

${ }^{24}$ Fleury, Cinquante ans de l'histoire, ob. cit., pp. 340 y 342. 
el antecoro era el lugar de encuentro entre la comunidad religiosa celebrante y la comunidad laica expectante. Si el coro se ubicaba en la nave, dejando un amplio tramo que lo distanciaba de la capilla mayor como se generalizó en la Península Ibérica entre los siglos XV y XVI, era el tramo de crucero el que acogía los cadalsos para celebrar liturgias teatralizadas. Son conocidos los que se construyeron en Valencia, Zaragoza o en Toledo, en las embocaduras de los brazos del transepto, donde se escenificó la Anunciación, el Nacimiento o la profecía de la Sibila (Fig. 7). También había tablados en la Navidad de la catedral vieja de Salamanca, y era descrito en la introducción de la Farsa del juego de cañas de Sánchez de Badajoz, sito frente al coro de una hipotética catedral pacense para "que todo el auditorio lo vea" 25 . Esta misma estructura de madera fue la que se utilizó en Laon para situar el exorcismo público.

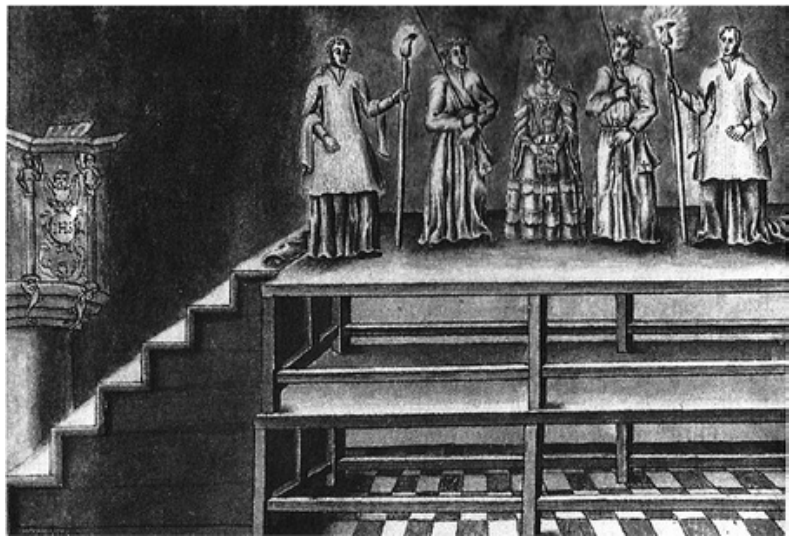

Fig. 7. Pedro Morales. Representación de la Sibila en la catedral de Toledo (ca. 1785).

En este punto, me gustaría llamar la atención sobre el franciscano que, sobre el púlpito y frente al cadalso del exorcismo, explica la escena frente a la agolpada muchedumbre, que hizo peligrar la estructura del propio jubé, como recogía el deán Héricourt, presente en los acontecimientos ${ }^{26}$. El predicador y sus fieles son una isla dentro de la representación general, rodeados por la elipse que narra la historia desde la entrada de la pobre Nicole en la catedral, la misa, el paso de la endemoniada por el tablado del exorcismo y su salida final, agotada, en un lecho transportado por seis hombres. En un acto sacro público de estas características, nuestro predicador es más que nunca un cronista de su entorno, un narrador para explicar los acontecimientos terribles

\footnotetext{
${ }^{25}$ Eduardo Carrero Santamaría, «Entre el transepto, el púlpito y el coro. El espacio conmemorativo de la Sibila», en La Sibila. Sonido. Imagen. Liturgia. Escena, ed. de Maricarmen Gómez y Eduardo Carrero, Madrid, Alpuerto, 2015, pp. 207-260.

${ }^{26}$ Roger, Histoire de Nicole de Vervins, ob. cit., p. 227.
} 
que iban a suceder. Me interesa muy especialmente el uso que parece hacer de las escenas como espejo o ilustración de un relato. El exorcismo se realizó durante varios días, mientras el grabado sintetizó el desarrollo del proceso en Laon, casi del mismo modo a la táctica narrativa de los predicadores lo hacía desde los púlpitos, usando imágenes como hizo Diego de Valadés en la Nueva España: indicando la imagen de los hechos explicados con su puntero (Fig. 8) De este carácter narrador, explicativo, dilucidador de la predicación del franciscano nos deja clara muestra el epígrafe respectivo a su público $(\mathrm{N})$ : «Y el pueblo católico, con la cabeza descubierta, se confirma en la fe, agradece a Dios y alaba el milagro, pero el hugonote con la cabeza cubierta dice tratarse de un trabajado engaño (ieu industrieux)».

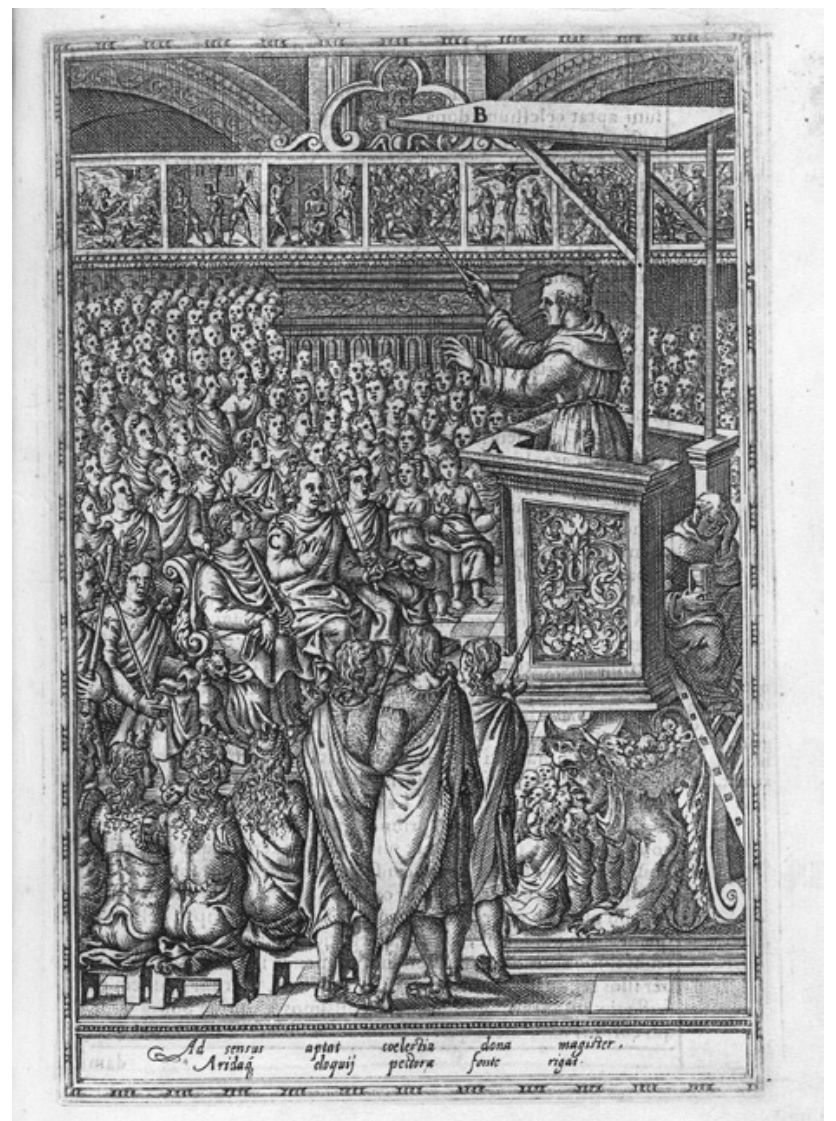

Fig. 8. Diego de Valadés, Rhetorica christiana ad concionandi et orandi vsvm accommodata, 1579, Typ 525.79.865, Houghton Library, Harvard University. 
Junto a este público a pie de púlpito, el grabador representó, en el alzado tetrapartito de la nave de Laon, más espectadores distribuidos entre la tribuna y el triforio. Este tipo de espacios en alto sólo eran practicables en circunstancias concretas, festividades de especial importancia, en que podían abrirse para a acoger a los fieles. Recordemos que un uso semejante del triforio también se documenta en la catedral Reims durante la ceremonia de coronación real, abierto al público que quería contemplar los actos. O en Burgos, cuando el triforio de la catedral fue accesible para aquellos privilegiados que pudieron contemplar la entrada de Felipe II en la catedral en 1593. Un exorcismo público también era un acto muy especial y por tal se tuvo en Laon, con sus tribuna y triforio ocupados por el público que observa y gesticula ante el rito llevado a cabo en el antecoro. También hay un hecho básico y es que la tribuna de Laon cuenta con dos capillas altas que duplican en altura las abiertas en los brazos del transepto. Ambos espacios son lo suficientemente elocuentes de un uso litúrgico de la tribuna y la consecuente, aunque indocumentada, existencia de un régimen de acceso a la misma, reglamentado por el cabildo. En tal caso, la presencia de personas contemplando el auténtico espectáculo del exorcismo desde las tribunas no sería en absoluto extraño. El hecho de que, entre éstos, tres parejas mixtas charlen y señalen la escena entra dentro de la imagen de repertorio y el costumbrismo que caracteriza todo el grabado. No parece, por tanto, que busque intencionadamente el trasfondo amoroso en la catedral, a la manera de las representaciones de prostitución en los teatros, de los grabados que acompañaron las primeras ediciones impresas de las comedias de Terencio ${ }^{27}$. De hecho, esta visión fascinada por una catedral que no es un lugar estático, si no profundamente dinámico, no debe ver con ojos contemporáneos la realidad cultual y festiva de la Edad Media y comienzos de la Moderna. La liturgia -que no teatro- hacía cambiar constantemente el aspecto de la catedral, llevando a elevar tablados y cadalsos, a descolgar artefactos y a vestir y desvestir su arquitectura. Por otro lado, las iglesias eran lugares con un marcado carácter social, en el que se enseñaba, se comerciaba, se entablaban relaciones sociales e, incluso, se llegó a vender ganado o a jugar a la pelota, como se documenta en Estrasburgo o en Mondoñedo ${ }^{28}$. De este aspecto vital de la catedral se hace claro eco nuestro grabado. Junto a las gentes que acompañan la procesión o que, en el fondo de la composición, circulan por su interior, en el antecoro a la derecha del retablo de la Virgen del Púlpito, tres personajes charlan ante una credencia abierta en el muro, en

\footnotetext{
${ }^{27}$ Weigert, French Visual Culture, ob. cit., p. 200.

${ }^{28}$ Véanse aquí las páginas que le dedicaron al tema Dieter Kimpel y Robert Suckale, L'architecture gothique en France 1130-1270, París, Flammarion, 1990, pp. 256-260.
} 
tanto que en una mesa tres clérigos venden reliquias y pequeñas imágenes dispuestas sobre una mesa, imagen de la costumbre y lo cotidiano.

Indudablemente, hay mucho de doctrinal en el impreso, en el grabado y en la historia que narró Jean Boulaese, pero no lo considero una fuente para el teatro medieval y sí para la puesta en escena de la liturgia. Preguntémonos aquí a qué liturgia dramatizada nos referimos: ¿a la del intercambio de tropos por cantores? ¿a cuando dichos cantores se vestían de los personajes a los que daban voz? ¿a la creación de dioramas escenográficos con figuras y tallas móviles, que ocupaban transitoriamente los altares? ¿o a juegos dramatizados, con guion, utilería y escena? Bien es cierto que el tablado sito en el trascoro nos recuerda otras construcciones efímeras semejantes, destinadas a liturgias teatrales o, directamente, a teatro, pero es que ambas manifestaciones escénicas compartían elementos de atrezo. El grabado de Laon no es más que la ilustración de un acontecimiento real, un acto sacro que sucedió en la catedral, con poco o nada de teatral y mucho de dramático. Fue un exorcismo convertido en espectáculo, algo participativo para unos fieles que marchan en procesión, escuchan el sermón o -tanto crédulos como escépticos- atienden al escalofriante rito, a pie de cadalso y desde la tribuna y el triforio de la catedral.

Recibido: 8/05/2017 Aceptado: 15/07/2017 


\title{
$\cos$
}

\section{ESPACIO LITÚRGICO MEDIEVAL VS. ESCENA. El ANTECORO DE LA CATEDRAL DE LAON y El EXORCisMo PÚBlico DE Nicole OBRy}

RESUMEN: En 1566, el exorcismo de la joven Nicole Obry fue utilizado por el catolicismo francés como argumento de debate en contra de la crítica reformista de los hugonotes al culto a la Eucaristía y a los Santos. A tal fin, el caso de posesión se difundió como un milagro eucarístico, para el que se redactaron varios textos y se diseñaron dos grabados. En uno de éstos, se representó sintéticamente la larga ceremonia del exorcismo llevado a cabo en la catedral de Laon, sobre un tablado elevado en el antecoro de la catedral. Este artículo trata sobre las implicaciones arquitectónicas y litúrgicas del grabado en nuestra comprensión de la catedral medieval, frente a su consideración como fuente para la historia del teatro.

Palabras clave: Laon. Antecoro. Jubé. Coro. Espacio. Catedral. Arquitectura. Exorcismo. Liturgia. Teatro.

\section{Medieval Liturgical Space vs. Staging. The Choir Screen of the Cathedral of Laon and the Public Exorcism of Nicole Obry}

\begin{abstract}
In 1566, the exorcism of the young Nicole Obry was used by the French Catholicism as argument of debate against the reformist critic to the cult to the Eucharist and the Saints. To this end, this case of diabolic possession became a Eucharistic miracle, for which several texts were written and two engravings were designed. In both engravings, there were represented the long ceremony of the exorcism carried out in the cathedral of Laon, but in the second one they draw a synthetically represented image of the whole process, over a scaffold next to the quire-screen of the cathedral. This article deals with the architectural and liturgical implications of this second engraving in our understanding of the medieval cathedral, as opposed to its consideration as a source for the history of theater.
\end{abstract}

Keywords: Laon. Quire-screen. Jubé. Choir. Cathedral. Architecture. Exorcism. Liturgy. Theatre. 